\title{
Urological Problems in the Management of Quadriplegic Women
}

\author{
R. Lindan, M.B., B.S., ${ }^{1}$ E. J. Leffler, R.N., ${ }^{1}$ D. Bodner, M.D. ${ }^{2}$ \\ ${ }^{1}$ Spinal Cord Injury Unit, Highland View Hospital, 3395 Scranton Road, Cleve- \\ land, Ohio, 44109, ${ }^{2}$ Division of Urology, Case Western Reserve University School \\ of Medicine, 2065 Adelbert Road, Cleveland, Ohio, 44106, U.S.A.
}

\section{Summary}

During the past 25 years enormous progress has been made in the management of the neuropathic bladder, largely as a result of the adoption of intermittent catheterisation, together with improvements in catheter-related techniques, and the judicious use of antibacterial drugs and sphincter surgery.

A few quadriplegic women can be trained to do self-intermittent catheterisation, using a special technique. For the majority of these women, however, there is no practical alternative at present to indwelling catheters. Bladder spasms resulting from the mechanical stimulation of the catheter and/or repeated infections may be difficult to control, and illustrative cases demonstrating some problems encountered are presented.

There is an obvious need for an external collecting device for these women. The developments in the field of such devices are presented and evaluated.

Key words: Tetraplegic women; Bladder management.

\section{Introduction}

The management of the paralysed bladder in patients with neurologic injuries has been revolutionised in the past 25 years. We rarely see ileal diversions; suprapubic drainage has largely been abandoned and, for paraplegic patients, selfintermittent catheterisation enables them to go without drainge apparatus and to remain infection free. Improved drugs and surgical techniques have overcome the problem of the dyssynergic urethral sphincter in male patients, and quadriplegic men can attain balanced bladder function and void independently through an external drainage sheath. Anterior sacral root stimulation offers the possibility, for those patients able to transfer to a toilet, of attaining an almost 'normal' bladder function. (Brindley et al., 1982).

The majority of quadriplegic women however are still where we started, with the permanent indwelling urethral catheter and its attendant problems of repeated infections and reflex bladder spasms. 


\section{Study group}

A recent survey of 38 quadriplegic women who attend our follow-up clinics showed that 33 still use Foley catheters. One patient had to have an ileal loop diversion because of uncontrollable bladder spasms. One patient elects to wear diapers. Only two patients are able to do self-intermittent catheterisation, and a third has it performed by a devoted sister. The majority were C5/6 complete injuries, which means they have minimal hand function and limited ability to transfer independently (Table).

\begin{tabular}{lrl}
$\begin{array}{l}\text { Table Level of injury of } \\
\text { women in study group }\end{array}$ & \\
\hline $\mathrm{C}_{4}$ & 6 Complete \\
$\mathrm{C}_{56}$ & 1 Incomplete \\
$\mathrm{C}_{78}$ & 28 Complete \\
& 1 Incomplete \\
\hline
\end{tabular}

Problems which we have encountered due to reflex bladder spasms in quadriplegic women include one 29 year old woman who extruded her catheter with the balloon intact on several occasions with tearing of the bladder neck and urethra. This resulted in the formation of a retropubic abscess and osteomyelitis of the pubic bones (Fig. 1).

A 58 year old woman, undergoing a routine cystogram, became unconscious after $50 \mathrm{ml}$ of contrast material was injected. She had previously exhibited severe allergy to IVP dye. The X-ray picture shows the catheter balloon in the proximal urethra, which was badly torn and permitted the dye to leak into the circulation (Fig. 2).

A 70 year old woman came to us 18 years post-injury on no antispasmodic drugs, leaking urine continuously and occasionally expelling the catheter balloon. She had pressure sores and maceration of the perineal skin. Her bladder capacity was only $50 \mathrm{ml}$ and she had inserted a large catheter with a $30 \mathrm{ml}$ balloon in the hope of stopping the leaking (Fig. 3). Her renal function was markedly decreased, particularly on the right side. This was ultimately reversed with the use of an antispasmodic drug.

Although we have anticholinegic drugs, which can control bladder spasms in the majority of patients, the side effects of dry mouth and blurred vision experienced with larger doses can become intolerable.

Removal of the Foley catheter and freedom from infection reduces bladder spasms, and 3 of our quadriplegic patients are on intermittent catheterisation, two of them on self-catherisation. One has a complete C7 lesion, the other an incomplete $\mathrm{C} 4 / 5$. Both of them are light weight and highly motivated and prepared to expend the energy required for transfers to the bed or toilet. We trained them both, using halved plastic vaginal specula, in which a small hole had been bored at the site of the urethal meatus. Using this, and a mirror, enabled them to keep the labia apart and locate the meatus without contaminating the tip of the catheter. The third patient, a nurse with a complete C5 lesion, has persuaded her sister to catheterise her four times a day. At night 


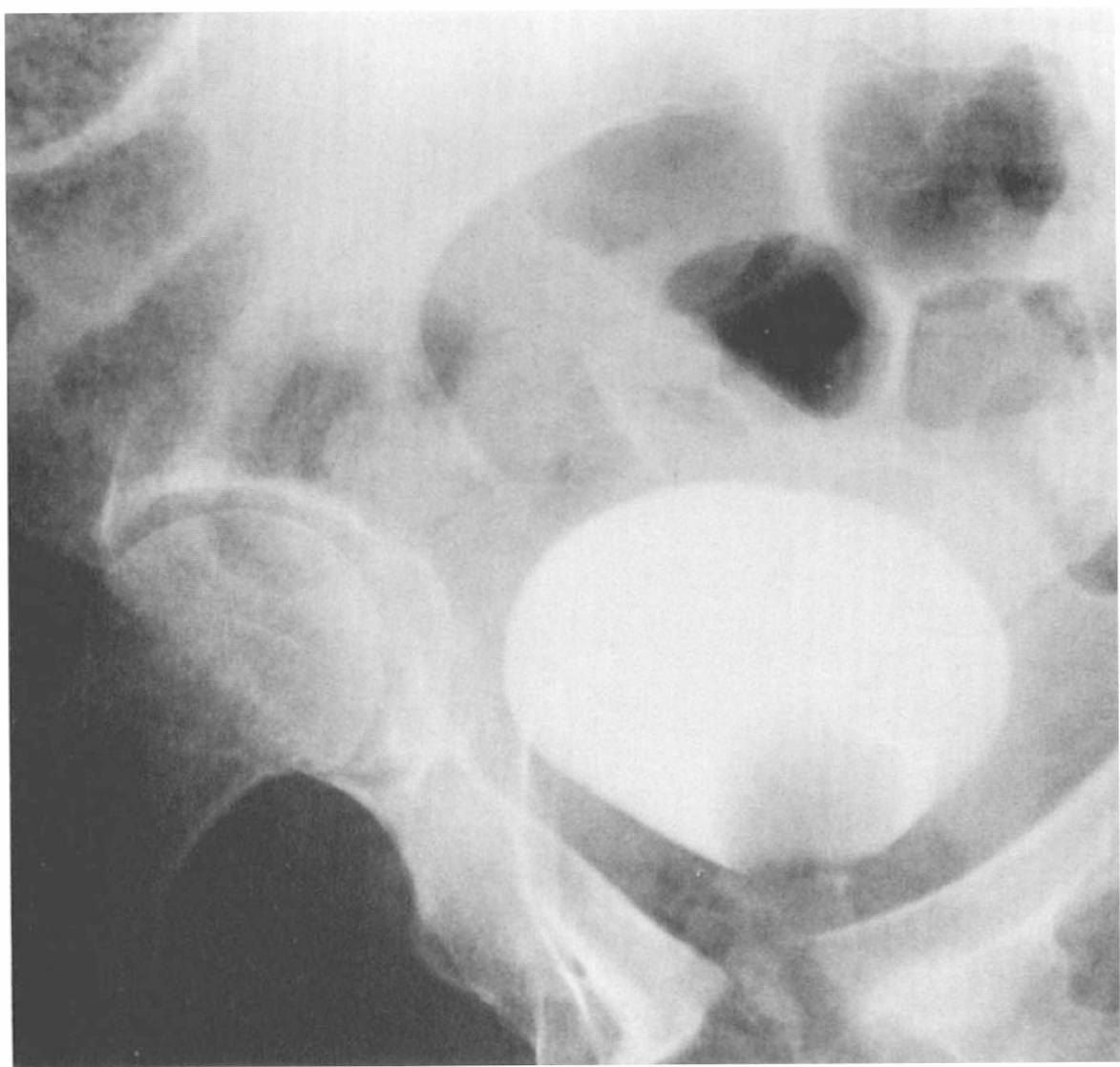

Figure 1 Contrast radiograph showing a retropubic abscess and osteomyelitis of the pubic bones.

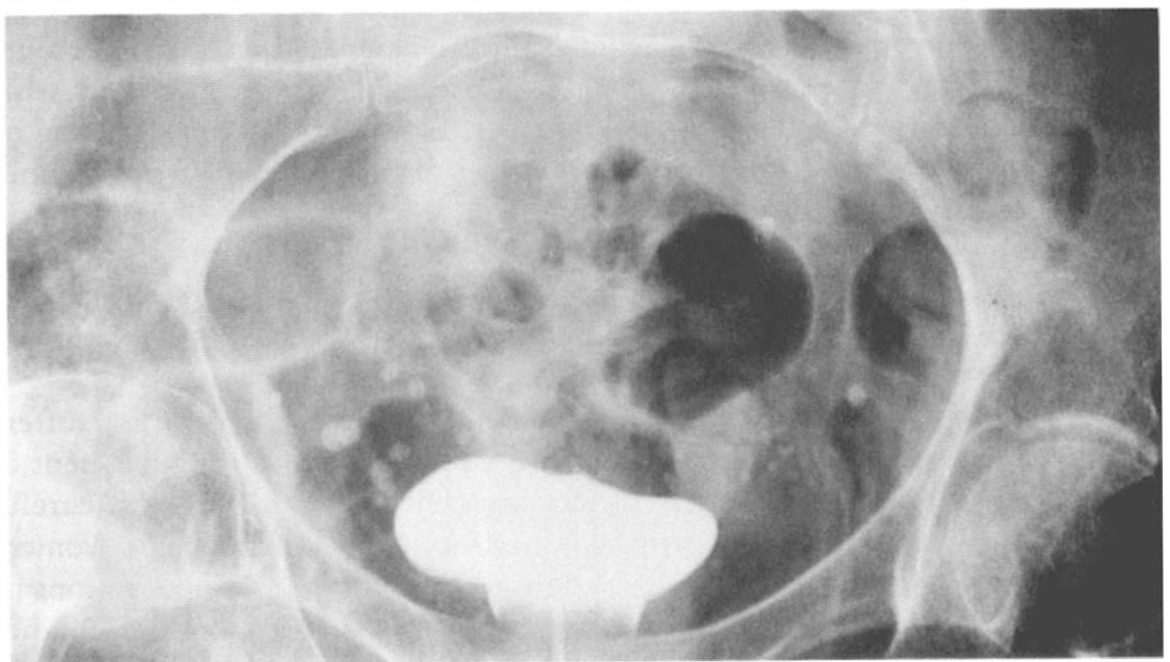

Figure 2 Contrast radiograph showing evidence of a torn proximal urethra. 


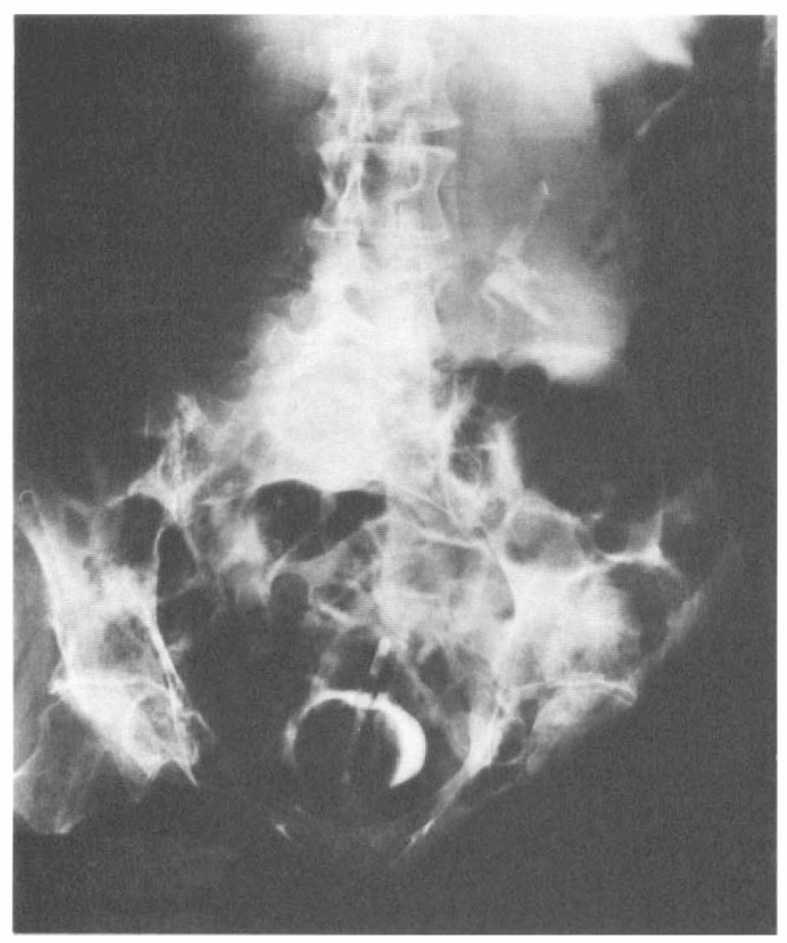

Figure 3 Contrast radiograph showing a contracted urinary bladder.

when she diureses, she lies prone with an external collecting device in place, allowing her sister to sleep.

\section{External drainage devices}

The external devices for paralysed women have been evolving slowly, because of apparent lack of interest on the part of the medical profession and what industry perceives as a relatively small market. For many years there was no advance beyond the classic device of the 1900s. This remained available until quite recently, but is quite unsuitable for paralysed women, who can get skin breakdown from its use.

Our own attempt at a solution was deemed potentially unprofitable by the manufacturer and adapted for use by women with stress incontinence, who are obviously more numerous (Lindan, 1970, 1984).

An adhesive device which has recently appeared on the U.S. market suffers from a limited flow capacity and tendency to come unstuck with movement of the panty, or sliding board transfers. Replacement requires time and careful cleaning of the device and the perineal skin. One of our quadriplegic women, carrying out self-intermittent catheterisation, uses it only for social occasions or travel, and finds self-intermittent catheterisation less time consuming for her every day routine.

Anterior sacral root stimulators may have a role to play, in that the high flow 
rates usually seen in women with suprasacral lesions and in those with multiple sclerosis could be reduced somewhat, and voiding through an external device could be better controlled.

The development of a satisfactory external device is not beyond the bounds of possibility, but because of the relatively small market of multiple sclerosis and quadriplegic women it will probably have to be funded from other than commercial sources.

Interested members of the medical profession in societies such as this, and the International Continence Society, surely have a role to play in bringing about more research and development in this area.

\section{Conclusions}

Urologic management of the quadriplegic female should be consistent with life style and attempt to minimise energy and cost.

Intermittent catheterisation should be used when the patient can assume the activity or under selective family circumstance.

Long term complications of indwelling catheters will persist until better external urinary collection devices are developed for women.

\section{References}

BRINDLey GS, Polkey CE, Rushton DN 1982 Sacral anterior root stimulators for bladder control in paraplegia. Paraplegia 20(6):365-81.

LINDAN R 1970 The Design and Preliminary Trials of an External Appliance for Women with Neurogenic Bladder Dysfunction. Proceedings of XVIII Veterans' Administration Spinal Cord Injury Conference pp. 101-104.

Lindan R, NeDdleman S 1984 Design and testing of an external urinary collecting device for incontinent women. Proceedings of the International Continence Society. Fourteenth Annual Meeting, p. 82-84. 